DOI: 10.20472/IAC.2018.040.001

\author{
NAWAZ AHMAD \\ The University of Lahore, Pakistan
}

\title{
ETHNIC DIVERSITY, STRESSFUL LIVING ENVIRONMENT AND INTERNATIONAL TRADE
}

\begin{abstract}
:
Ethnic diversity plays a crucial role in sustainable development of any country. But segregation, discrimination and bigotry are increasing gradually across the world and making it not much difference from prejudice to social exclusion. This empirical study aims to investigate whether existing ethnic or religious diversity may create a more stressful living environment by using the data of 187-countries i.e. 56-high income, 102-middle income and 29-low income countries of the world. The study concludes that ethnic diversity creates a more stressful living environment. However, negative standing of stressful living environment with international trade is witnessed through empirical observations. The study also found positive and significant relationship between ethnic diversity and stressful living environment. Despite the fact that diversity cannot be reduced, however; its effects can be minimized by providing equal opportunities and peaceful society which later ensures well-being of people by means of cohesiveness.
\end{abstract}

\section{Keywords:}

Ethnic diversity; Religious diversity; Stressful living environment; Economic development

JEL Classification: F10, J15, 011 